\title{
When Is an Alternative Not an Alternative? Supporting Progress for Absolute Replacement of Animals in Science
}

\author{
Craig Redmond \\ Lush Prize Management Team, Manchester, United Kingdom \\ craig@lushprize.org
}

Despite a great deal of talk about "alternatives" to animal testing, and "replacing" animal use, there are no clearly agreed upon definitions for these terms. This has led to extensive numbers of animals used and accepted as "alternatives" - including zebrafish, invertebrates, animal tissues, embryos, sera, and animals' eyes - despite the obvious fact that they will suffer and/or be killed for these methods. Instead, there is a confusing array of reference to live animals, vertebrates, and mammals being termed as "less sentient" or "conscious" species.

Much of the discussion on alternatives is still based around Russell and Burch's (1959) 3Rs; although few, if any, of the definitions currently in use match their original writings, which were designed to be a foundation for future discussions. In the European Union (EU), Directive 2010/63/EU on the protection of animals used for scientific purposes defines its aim as representing "an important step towards achieving the final goal of full replacement of procedures on live animals for scientific and educational purposes, as soon as it is scientifically possible to do so" (European Parliament, 2010, Recital 10). Although this is a progressive step forward compared to previous legislation, use of the word live is often overlooked, as are so many other obstacles to a true end to all animal use in laboratory research. Talk of "replacing animal testing" and "alternatives" comes with little discussion about what those phrases actually mean; while researchers continue to use animal sera, tissues, and live animals that are perceived as less sentient.

This chapter addresses some of the areas in which animals are still used within "alternatives"-based research and calls on animal welfare and in vitro organizations to lead the debate and encourage absolute replacement of animal

(C) CRAIG REDMOND, 2019 | DOI:10.1163/9789004391192_028 
use in research. Without this, progress to end animal research will always remain limited, despite the paradigm shift seen in recent decades.

\section{$2 \quad$ Russell and Burch}

Russell and Burch's concept of the ${ }_{3}$ Rs was no doubt radical when their book, The Principles of Humane Experimental Technique, was published in 1959 (hereinafter referred to as The Principles). Alan Goldberg (2010, p. 25), Founding Director of the Center for Alternatives to Animal Testing (CAAT), called it, "a monumental contribution". A special edition, containing the original text, was reissued in 1992; and an abridged version was translated into Mandarin and provided to Chinese public libraries and universities for free in 2014. The ${ }_{3}$ Rs have also been enshrined into EU legislation on animal experimentation. While The Principles has undoubtedly been vital to the discussion on animal research over the past 60 years, how relevant is it to the current situation? Has the scientific community, which often refers to the 3 Rs, actually taken much of Russell and Burch's advice on board? These questions are pertinent because, as Tannenbaum and Bennett (2015, p. 120) commented, "The Principles was presented not as the final word of this science but as a foundation for future developments".

Russell and Burch (1959/1992) defined the ${ }_{3}$ Rs as replacement: "the substitution for conscious living higher animals of insentient material"; reduction: "reduction in the numbers of animals used to obtain information of a given amount and precision"; and refinement: "any decrease in the incidence or severity of inhumane procedures applied to those animals which still have to be used". This chapter focuses on replacement, and how the terms replacement and alternatives to animal experimentation are defined across the scientific and non-governmental organization sectors.

\section{Replacement: Relative and Absolute}

Russell and Burch defined replacement as "any scientific method employing non-sentient material" that may replace the use of "conscious living vertebrates". Tannenbaum and Bennett (2015, p. 126) add that replacement, "is defined as the use of insentient (or non-sentient) material instead of sentient material. Russell and Burch do not define replacement as not using animals because they classify the use of insentient animals as instances of 
replacement. They distinguish between what they call relative and absolute replacement."

\subsection{Relative Replacement}

"In relative replacement, animals are still required, though [...] they are exposed, probably or certainly, to no distress at all. In absolute replacement, animals are not required at all at any stage. It follows from what has been said earlier that absolute replacement may be regarded as the absolute ideal" (Russell and Burch, 1959/1992). Relative replacement may include: "non-recovery experiments on living and intact but completely anesthetized animals"; "experiments in which animals are still required but only to furnish preparations after being painlessly killed"; and "work on the isolated cells, tissues, or organs of vertebrates" (Russell and Burch, 1959/1992). The Institute for Laboratory Animal Research (ILAR) (ILAR, 2011, p. 5) refers to relative replacements as "replacing animals such as vertebrates with animals that are lower on the phylogenetic scale". ILAR is not unique in its deviation from Russell and Burch's definition, as it appears common for species of "lower sentience" to be considered as (relative) "replacements", without any obvious consideration or discussion of what less sentient means or what evidence it is based on. This is perhaps one of the reasons why, in recent years, zebrafish have been promoted as an alternative, as the following example shows: "another 3 Rs approach involves the replacement of more sentient vertebrates with animals thought to have a lower potential for pain perception, such as the amoeba Dictyostelium discoideum, fruit fly Drosophila melanogaster and zebrafish" (Tanner and McShane, 2016, p. 3). The examples that Russell and Burch gave of species they considered to be replacements ("the more degenerate metazoan endoparasites") were included because they believed "that they are completely non-sentient, not because they are less sentient" (Tannenbaum and Bennett, 2015, p. 127).

\subsection{Absolute Replacement}

"Turning to absolute replacement, we may distinguish four main subdivisions: the use (outside the vertebrate body) of metazoan endoparasites; higher plants; microorganisms (protozoa, bacteria, molds, etc.); and nonliving physi$\mathrm{cal}$ and chemical systems. First, there is the study of metazoan endoparasites (nematodes, cestodes, and trematodes) in vitro, as opposed to their study in the living vertebrate host" (Russell and Burch, 1959/1992). Provisions were still made in The Principles for the use of members of the animal kingdom within absolute replacement, whereas the more widely accepted opinion now is that no animal or animal-derived material be involved (Gunatilake, 2016; Lidbury and Richardson, 2012). The replacement models that have so far been 
introduced by the scientific community are mostly relative, not absolute, and more encouragement needs to be given to progress further in this area. Scientific conferences on alternatives to animal use often seem to focus on reduction and refinement, with very little discussion on replacement. Michael Balls, of the Fund for the Replacement of Animals in Medical Experiments (FRAME) noted that, "it is impossible to avoid the conclusion that it [replacement] is the forgotten R, even though Russell and Burch saw it as of great importance" (2010, p. 21). Balls added that there is "a danger that refinement can be used as a convenient way of showing commitment to the $3 \mathrm{Rs}$, whilst ensuring that animal experimentation is seen as respectable and can be allowed to continue, while the fundamental ethical questions raised by it are avoided".

\section{What Is an Alternative?}

Are "alternatives" and "replacement" the same thing? The United States Department of Agriculture (USDA) (2017) refers to alternatives as "a term that has different meanings to different people and this difference largely depends on which side of the issue one is found". "Alternatives" are generally based on the ${ }_{3}$ Rs, although the terms "alternatives" and "alternative methods" never occur in The Principles. The word "alternatives" should be considered to only refer to Replacement, yet this is not how it is always viewed.

The European Union Reference Laboratory for Alternatives to Animal Testing (EURL ECVAM) (2017) defines "alternative" as "generally associated with the Principles of the ${ }_{3} R s[\ldots]$ In this context an alternative method serves to fully replace an animal test, to reduce the number of animals needed in a test, or to refine an animal testing procedure in order to reduce pain and suffering." In its "step-by-step approach to an alternatives search," CAAT suggests that, in addition to cell culture and tissue culture, researchers "might look for non-mammalian animal models-fish or invertebrates, for examplethat would still give you the data you need" (Center for Alternatives to Animal Testing, n.d.). However, even using mammals is not always ruled out. The UK Government has referred to transgenic mice being used "to replace non-human primates" in oral polio vaccine safety tests (Home Office, 2014, p. 14). The EU-funded, RETHINK project evaluated the potential for minipigs "as an alternative approach" to using dogs and non-human primates in regulatory toxicity testing that can contribute to the 3 Rs. Although the argument was made that this met the criteria for refinement, Forster et al. (2010) noted that, "the concept of replacement does not embrace the notion of replacing one class of sentient mammal (e.g. primates) by another (minipigs)" (p. 239). 
Others consider a non-animal approach to be one that does not use live animals (Clippinger et al., 2016, p. 453). AltTox.org (2017), "a website dedicated to advancing non-animal methods of toxicity testing" lists "alternative methods" for assessing eye irritation/serious eye damage for regulatory testing purposes, some of which still use animals, including cow, rabbit, and chicken eyes.

So, does the term "alternative" apply to any of the 3 Rs, all live animals, mammals only, or perhaps just vertebrates? The terms "alternatives to animal testing", as well as "replacement", appear to be used very loosely by stakeholders on all sides of the discussion. While the general public are often led to believe, or at least not corrected when they do believe, that these terms mean that no animal use whatsoever is involved, this is all too often not the case. Philosopher Joel Marks (2012, p. S18) writes that "the so-called alternatives movement commonly contains a fatal loophole. For while a layperson may assume that the term 'alternative' refers to the use of some wholly nonanimal method of research [...] in fact, it often means an animal 'down the phylogenetic scale". Marks believes that, "it is really only full replacement of animals in biomedical research that merits the name 'alternative'. Any alternative to that understanding of 'alternatives' is unjustified, not only in word but in deed." (2012, p. S18).

animal [...] a. A living organism which feeds on organic matter, typically having specialised sense organs and a nervous system and able to respond rapidly to stimuli; any living creature, including man. [...]

b. In ordinary or non-technical use: any such living organism other than a human being.

Oxford English Dictionary, 2016

Legislation to protect animals used in laboratory experimentation does not protect all animals. Directive 2010/63/EU (European Parliament, 2010), the key EU legislation relating to animals used for scientific purposes, applies to the following animals (Article 1 (3)): "1. (a) live non-human vertebrate animals, including: (i) independently feeding larval forms; and (ii) foetal forms of mammals as from the last third of their normal development; 2. (b) live cephalopods." The Animal Welfare Act (AWA) regulates the use of animals in laboratories in the United States as well as other animal use, including zoos and circuses. The term animal in the AWA includes specific species in some, but not all, situations and specifically excludes rats of the genus rattus and mice of the genus mus as well as birds used in research (USDA, 2017). AWA also excludes 
cold-blooded animals (fish, reptiles, and amphibians), as well as farmed animals used in agricultural research (e.g., cows and pigs); as such fewer than $10 \%$ of animals in us laboratories are covered by the AwA (New England AntiVivisection Society, 2017). Mice alone make up more than three-quarters of the animals used by the top federally-funded us test centers (Kaiser, 2015). Other countries have different legislation on what species (if any) are protected in experimentation.

"Alternatives" that Still Exploit Animals

\section{1 $\quad$ Fish}

There has been a greater increase in the use of fish in research in the Eu than any other species (European Commission, 2013, p. 9). In the United Kingdom, fish are the second most used animals after mice (Home Office, 2015, p. 11). Zebrafish (Danio rerio) have been the focus of much attention, and they now account for $50 \%$ of all fish used in UK laboratories, partly due to the availability of genetically altered zebrafish for use in basic and applied biomedical research (Home Office, 2015, p. 23). A major reason for the increase in the use of zebrafish is their reduced cost compared to mammals (Reed and Jennings, 2011, p. 14; maintenance costs are less than $1 / 1,000$ th of the cost for mice); and a pair of zebrafish can produce 100-300 eggs per week, making their embryos a "suitable model" for high throughput screening (van Vliet, 2011, p. 24). Zebrafish have now become established as a "widely accepted relative replacement model" (Gunatilake, 2016).

Researchers at the University of British Columbia reviewed existing literature on public acceptance of using particular species in laboratories and found that fish and invertebrates were "typically rated below mammals, and, as such, are often considered an appropriate replacement for mammals in research" (Ormandy, Schuppli and Weary, 2012, p. 321). Although their own study found that when the research was deemed to cause pain to zebrafish (specifically when it came to ENU mutagenesis) survey participants objected to it (p. 331), it may explain why even some in vitro organizations promote the use of zebrafish (Gunatilake, Busquet and Akbarsha, 2014; M'Barek et al., 2015). Sweeping statements are often made in support of using fish instead of mammals in research, with no real attempt to back them up. Planchart et al. (2016, p. 435) claim that, "Small freshwater fish models, especially zebrafish, offer advantages over traditional rodent models, including [...] reduced animal welfare concerns". An article on the website of the British Association of Zebrafish Husbandry claims that, "their mental and physical concerns may be deemed less than those of 
a rodent for example [...] Because of the widespread use of the unprotected larval form of zebrafish there is currently little emphasis on replacing aspects of this use" (Nicholls, 2012).

In the UK, the Royal Society for the Prevention of Cruelty to Animals (RSPCA) has highlighted concerns over zebrafish use in research (Reed and Jennings, 2011), including:

- Specific husbandry requirements are still poorly understood.

- The majority of experiments, which involve embryonic and early larval (less than six days post-hatching) stages, would not be covered and reported by legislation.

- Some practices do not require reporting in the annual Home Office statistics, including the humane killing of zebrafish by an approved method in order to obtain tissues, organs, sperm or eggs; and the use of zebrafish in breeding programs (unless they are genetically modified).

Evidence that fish, like all vertebrate animals, feel pain was first presented almost 40 years ago (RSPCA, 1980). The UK government's Farm Animal Welfare Committee (1996) subsequently acknowledged that fish experience fear, stress, and pain when removed from water; and that the physiological mechanisms in fish for experiencing pain are very similar to those in mammals. More recently, fisheries professor, Victoria Braithwaite (2010) wrote that, "I have argued that there is as much evidence that fish feel pain and suffer as there is for birds and mammals - and more than there is for human neonates and preterm babies". Fish behavior and welfare scientist, Yue Cottee, added (2010) that, "We now have logical reason and scientific evidence to start treating fish as sentient creatures" (p. 13); and "it now seems that the question to be asking is not 'Do fish have conscious awareness' but 'What is the level and nature of their conscious awareness?"” (p. 12). The RSPCA conclude that, "Although there has been little specific study involving zebrafish, given the above [evidence that fish feel pain], zebrafish should be given the benefit of any doubt" (Reed and Jennings, 2011, p. 41).

\subsection{Vertebrates in Early Developmental Stages/Use of Animal Embryos}

Under Directive 2010/63/EU (European Parliament, 2010), vertebrates only become protected animals at a particular stage in their development: the last third of gestation (mammals); incubation (birds and reptiles); or the stage when independent feeding occurs (amphibians and fish), for example, early chicken embryos in reproductive toxicity tests. Such cut-off points have been criticized as "arbitrary and unsatisfactory" and not based on any strong scientific basis (Balls, 1994, p. 197). 
The fish embryo toxicity (FET) test is considered "a possible alternative to the acute fish [toxicity] test" (PETA International Science Consortium, 2015a). This test exposes at least seven fish to the test substance for a period of 96 hours to record the concentrations that kill $50 \%$ of them $\left(\mathrm{LC}_{5} \mathrm{O}\right.$ ) (Organisation for Economic Cooperation and Development, OECD, 1992). FET uses 20 freshlyfertilized embryos per treatment or control (Chemical Watch, 2015), mostly zebrafish, fathead minnow, rainbow trout, bluegill, and Medaka. At an international symposium on using fish and amphibian embryos as alternative models, it was stated that, "In compliance with international animal welfare regulations, the fish and amphibian embryo models provide an ethically acceptable small scale analysis system with the complexity of a complete organism [...] The ultimate goal of the symposium is to promote the development of the fish and frog embryo models as potential alternatives to animal testing." (Helmholtz Centre for Environmental Research, 2016). A footnote to an article on the Chemical Watch website (2015) about FET highlights some of the ongoing confusion: "This article was amended on 17 April to clarify that the fish embryo toxicity (FET) test is not considered a replacement to animal testing, as fish embryos are animals. However, the use of fish embryos up to a certain age does not fall under Directive 2010/63/EU on the protection of animals used for scientific purposes."

\subsection{Body Parts}

Animal parts used as "alternatives" to animal testing (or classed as a "non-animal method" (Clippinger et al., 2016), include the eyes of animals slaughtered for consumption. Examples are the Bovine Corneal Opacity and Permeability assay (ВСОР), seen as a substitute for the Draize eye irritation test that uses live rabbits (in which a substance is instilled into one of the rabbit's eyes to assess injury for up to 21 days). The BCOP test method can be used to identify chemicals causing serious eye damage. The OECD (Organisation for Economic Co-operation and Development, 2017) states that the test "uses isolated corneas from the eyes of cattle slaughtered for commercial purposes, thus avoiding the use of laboratory animals". Along with the isolated chicken eye (ICE) and Isolated Rabbit Eye (IRE) tests, the BCOP assay is validated by regulatory bodies, including the OECD and Interagency Coordinating Committee on the Validation of Alternative Methods (ICCVAM), as well as promoted by in vitro and animal protection organizations (Humane Society International, 2013; Institute for In Vitro Sciences, 2014; PETA International Science Consortium, $2015 \mathrm{~b}$ ), although again there appears to be no discussion over the ethical considerations of this. 


\subsection{Invertebrates}

Invertebrates are generally exempt from any animal welfare legislation, and little consideration is given to their animal care requirements or suitability for captive conditions (Carere, Wood and Mather, 2011), with one exception. Since 2013, all cephalopod species (e.g., octopus, squid, and cuttlefish) used in research have been regulated within the EU by Directive 2010/63/EU (European Parliament, 2010), giving them the same legal protection as vertebrates because of their capacity to experience pain and suffering. Several other non-EU countries also regulate their use. Some reviewers believe that decapod crustacea (e.g., crabs, lobsters) may receive similar protection in the future "because of the continuing debate about their pain perception" (Fiorito et al., 2014, p. 15). The horseshoe crab, Limulus polyphemus, is used in the Limulus amoebocyte lysate (LAL) assay to replace the rabbit pyrogen test for the detection of endotoxin in Hepatitis B vaccines (Park et al., 2005). The rabbit test involves injecting the test substance into the ears of three rabbits (wHO, 2016). However, the LAL assay uses blood cells from the horseshoe crab, with up to $30 \%$ mortality due to bleeding (Leschen and Correia, 2010, p. 144).

Russell and Burch (1959/1992) stated that replacement means using completely insentient material, animal or non-animal. Tannenbaum and Bennett (2015, p. 127) noted that, "using animals that are less sentient [...] is inconsistent with their definition [...] They explicitly argue that, because of more limited mental capacities that prevent them from understanding and dealing with distressful experiences, for lower vertebrates a given level of distress is probably worse than it is for a higher vertebrate species."

\subsection{Animal-based Sera}

Fetal calf serum (also known as fetal bovine serum) is the most widely-used serum supplement for in vitro cell culture (Seralab, 2017). Bovine fetal blood is collected by cardiac puncture, performed by inserting a needle directly into the heart of the unanesthetized fetus in a specially provided area in the slaughterhouse (International Serum Industry Association, 2017). Other products are sold as a lower cost alternative and for veterinary vaccines, such as horse, goat, rabbit, porcine, and chicken serum (Thermo Fisher Scientific, 2017). Blood may be taken at the time of slaughter for consumption or obtained from what is euphemistically called "donor" animals, from whom blood is taken more than once.

In a survey of companies and laboratories involved with the collection and use of fetal calf serum (FCS), Jochems et al. (2002) concluded that:

- The time that elapses between death of the mother cow and the puncture was found to be up to 30 minutes, with the procedure of bleeding itself lasting another $2-5$ minutes. So, a bleeding procedure may last up to 35 minutes after the death of the mother (pp. 4-5). 
- It is very likely that the fetus is alive at the time of blood collection and "will experience pain and/or suffering at the moment of heart puncture for blood collection and possibly for a period after that, until it actually dies" (p. 8).

- "Exsanguination and cardiac puncture (penetrating skin, internal and external intercostal muscles, costal pleura, heart muscle, and heart pleura) are both graded as severe discomfort in unanesthetized post-natal bovines. From this, we have to conclude that the current practice of blood collection from fetal bovines causes suffering to these animals" (p. 11).

- The global number of bovine fetuses used annually is 1-2 million (p. 5). Oredsson (2013), a researcher at Lunds University, stated that, "The very use of fetal calf serum actually defeats the purpose of using cell culturing as replacement for animals in research". Jochems et al. (2002, p. 13) similarly argue that, "The thought that cell culture techniques requiring FBS are a replacement to the use of animals is a misconception."

\subsection{Antibodies}

Traditionally, antibodies against a specified target are produced by injecting the antigen into an animal and initiating an immune response (Afability, 2017). Animals are repeatedly injected with the molecule to be detected, initiating a hyperimmune response. An unknown number of animals (millions) are used worldwide to generate the antibodies that are extracted at a later stage for the detection of the molecule. Gray et al. (2016) note that, although the extracted antibodies are incorporated into an in vitro test, this traditional method is not a replacement of animal testing but simply buries the animal use "several layers deep in the production process, and our ultimate aim, to replace needless animal use, is not achieved" (p. 961). Gray and colleagues have called for the proper implementation of Directive 2010/63/EU, which requires that animals not be used when a non-animal alternative exists. They also recommend that the European Union Reference Laboratory for Alternatives to Animal Testing (EURL ECVAM) extends its activities to include the production of animalfriendly affinity reagents (AFAs) and their subsequent use (p. 967). In addition, there are reported concerns about the quality and unreliability of commercial, animal-derived antibodies (Groff, Brown and Clippinger, 2015, p. 1788); and scientists are being encouraged to use the non-animal affinity reagents that are available.

\subsection{Tissues}

Living material for vertebrate tissue culture has to be obtained from animals or humans. Although it may be sourced from animals killed for food (which, in itself, is an ethical issue to consider), it is more likely to be obtained from animals specifically-bred and killed for the purpose because of requirements, 
such as a sterile technique (Balls, 1994, p. 197). Data collected for EU Member States excludes animals killed solely to supply tissues for ex vivo or in vitro use; but for the six countries that Taylor et al. (2008, p. 331) obtained data, the average percentage of animals killed for their tissues was 21.1\%. Philosopher Joel Marks (2012, p. S18) considers it absurd that "the very same animal (both species and individual) can be used as an 'alternative.' This is due to two additional ambiguities. One of them is between an experiment on a whole animal and an experiment on tissue taken from an animal of the same species. The latter can be considered an 'alternative' but of course the animal is still bred, confined, and subject to various procedures".

\section{The Role of Regulatory Bodies in Promoting Animal-based Testing}

It has been shown that "alternatives" to animal testing do not always mean that no animals or animal substances are used. Many of the "alternatives" endorsed by EURL ECVAM, ICCVAM, and/or the OECD still use animals in some way, for example (PETA International Science Consortium, n.d.):

- Rat skin transcutaneous electrical resistance (TER) test for skin corrosion

- Murine local lymph node assay (LLNA) for skin sensitization

- Bovine corneal opacity and permeability (вСOP) test method and Isolated Chicken Eye (ICE) test method for eye corrosion/eye irritation

- Whole rat embryo toxicity assay for reproductive toxicity

- $\quad$ FET test and Daphnia sp., acute immobilization test for aquatic toxicity.

Scientists and organizations working on promoting absolute replacement of animal tests need to be proactive in ensuring that regulatory bodies are fully aware of these alternatives, and why their validation is preferable to those that currently exploit animals. This may involve training regulatory reviewers in the new methods.

A review of companies manufacturing antimicrobial cleaning products to discover why so few were submitting non-animal data for regulatory purposes (Clippinger et al., 2016, p. 455) found there was a lack of global regulatory acceptance (meaning that animal tests would likely be conducted anyway, since it was required by other countries or authorities); and uncertainty within industry about regulatory reviewers' familiarity with the framework and their ability to evaluate and interpret non-animal studies, which could influence the likelihood of acceptance. The authors concluded that, "Overcoming institutional inertia at companies and regulatory agencies requires collaboration among a motivated group of people across multiple sectors." (p. 455). The multistep process of implementation includes education of regulatory and industry personnel before a non-animal method is finally accepted. 
The Lush Prize is an annual prize fund supporting initiatives across science, campaigns, and regulatory lobbying to end the use of animals in research, particularly toxicology. A joint project between Lush Cosmetics and the Ethical Consumer Research Association, it provides £250,000 in funding each year in the main prize categories, with additional funds provided through regional awards in Asia and the Americas (Lush Prize, 2017a).

Unique in being a $\mathrm{R}$ award (focusing on absolute replacement as opposed to ${ }_{3} R s$ ), the Lush Prize has strict eligibility guidelines (Lush Prize, 2017b), including:

- "Non-animal research in this sense means no use of non-human animals (including all vertebrates and invertebrates) or primary animal cells, embryos, tissues, organs and serums. Human biology-based approaches are strongly encouraged, although the use of established cell lines of non-human animal origin shall not necessarily be excluded." (Immortalized cell lines can keep undergoing division, so no new animals are killed for them).

- "The prize money shall be ring-fenced for non-animal use so that it cannot be used to fund any animal testing whatsoever."

- "In awarding the prize to academic institutions, priority will be given to research teams or groups which deal exclusively with non-animal research."

The five categories of prize are designed to complement each other in breaking down the barriers to end animal testing. It supports science, so that scientist can come up with new tests; training, so that scientists can learn how to use the new tests, and young researchers can learn how to discover new tests early in their careers; lobbying, so that governments can be persuaded to make the new tests compulsory; public awareness, so that the governments can be pressured to make these changes (Lush Prize, 2016).

In addition to the financial support, the Lush Prize raises the profile of absolute replacement through an annual conference and a special edition of the Alternatives to Laboratory Animals journal, highlighting the work of awarded scientists who are helping to achieve the paradigm shift towards true replacement.

Whilst the issue of animal testing is the subject of a great deal of public discourse, there has been little discussion about what defines "replacement" or "alternatives". Regulatory bodies and many scientists working in "alternatives" are not particularly concerned about some of the animal use mentioned here. 
Their focus, as highlighted in Directive 2010/63/EU (European Parliament, 2010), is the use of live animals. What is of greater concern is the quiet acceptance, or even active promotion, of animal-based research by animal welfare and in vitro organizations. They should be setting the standards and always pushing for absolute replacement; otherwise, progress will remain limited.

The Lush Prize has begun to put this discussion on the agenda, not only with its strict eligibility criteria, but also through its conferences. Its 2014 conference was titled, Is One R the new Three Rs?, and asked "Does the consensus building around 21st Century Toxicology — a wholly replacement model $(\imath R)$ - mean that the ${ }_{3}$ Rs framework (refinement, reduction, replacement) is an idea that has had its day?" (Lush Prize, 2014). There needs to be honesty among regulators and the research community that the use of any animal product is not a complete replacement or an alternative, only then can there be encouragement to fully replace animal testing with ethical and reliable human-relevant models.

Russell and Burch's ${ }_{3} R s$ have played a crucial role in developing ideas on replacing the use of animals in experimentation, and much of what they wrote in 1959 is still valid today. However, we need to update the terms "alternative" and "replacement" to reflect our goal of completely ending the use of all animals in research and stop being complacent in thinking that partially replacing animal use is sufficient. It will be the role of non-governmental organizations and those scientists who truly believe in the goal of complete replacement to lead this progression, to agree on definitions and ensure that they begin to be used across all sectors, including industry and academia. As Tannenbaum and Bennett (2015, p. 120) commented, Russell and Burch did not see their writings as the final word on this but "a foundation for future developments".

\section{References}

Afability (2017). What Are Antibodies?. [online] Available at: http://www.afability.com/ services-view/what-are-antibodies/ [Accessed 2 January 2017].

AltTox.org (2017). Eye Irritation/Serious Eye Damage. [online] Available at: http:// alttox.org/mapp/toxicity-endpoints-tests/eye-irritationcorrosion/ [Accessed 4 January 2017].

Balls, M. (1994). Replacement of Animal Procedures: Alternatives in Research, Education and Testing. Laboratory Animals, 28(3), pp. 193-211.

Balls, M. (2010). The Principles of Humane Experimental Technique: Timeless Insights and Unheeded Warnings. Alternatives to Animal Experimentation, 27, pp. 19-23. 
Braithwaite, V. (2010). Do fish feel pain? Oxford, U k: Oxford University Press.

Carere, C., J.B. Wood and J. Mather (2011). Species Differences in Captivity: Where Are the Invertebrates? Trends in Ecology \& Evolution, 26(5), p. 211.

Center for Alternatives to Animal Testing (n.d.). Search for Alternatives. [online] Available at: http://altweb.jhsph.edu/resources/searchalt/index.html [Accessed 4 January 2017].

Chemical Watch (2015). Fish Embryo Toxicity Tests Satisfy REACH Requirements. [online] Available at: https://chemicalwatch.com/23558/fish-embryos-can-replace -fish-in-reach-testing [Accessed 26 September 2016].

Clippinger, A.J., E. Hill, R. Curren and P. Bishop (2016). Bridging the Gap Between Regulatory Acceptance and Industry Use of Non-Animal Methods. Alternatives to Animal Experimentation, 33(4), pp. 453-458. [online] Available at: https://www.altex.org/ index.php/altex/article/view/143/123 [Accessed 16 August 2018].

Cottee, S.Y. (2010). Are fish the victims of 'speciesism'? A discussion about fear, pain and animal consciousness. Fish Physiology and Biochemistry, 38(1), pp. $5^{-15}$.

European Commission (2013). Seventh Report from the Commission to the Council and the European Parliament on the Statistics on the Number of Animals Used for Experimental and Other Scientific Purposes in the Member States of the European Union. $\operatorname{COM}(2013) 859 /$ final. [online] Available at: http://eur-lex.europa.eu/legal-content/ EN/TXT/?uri=CELEX:52013DC0859 [Accessed 7 January 2017].

European Parliament (2010). Directive 2010/63/EU of the European Parliament and of the Council of 22 September 2010 on the protection of animals used for scientific purposes. Official Journal of the European Communities, L 276, pp. 33-79. [online] Available at: http://eur-lex.europa.eu/legal-content/EN/TXT/?uri=CELEX:32010Loo63 [Accessed 7 January 2017].

European Union Reference Laboratory for Alternatives to Animal Testing (EURLECVAM)(2017). Alternative Test Methods. [online] Available at: https://eurl-ecvam. jrc.ec.europa.eu/glossary/glossary/alternative-test-methods [Accessed 2 January 2017].

Farm Animal Welfare Council (1996). Report on the Welfare of Farmed Fish. Department for Environment, Food \& Rural Affairs, u K Government.

Fiorito, G., A. Affuso, D.B. Anderson, J. Basil, L. Bonnaud, G. Botta, A. Cole, L. D'Angelo, P. De Girolamo, N. Dennison and L. Dickel (2014). Cephalopods in Neuroscience: Regulations, Research and the 3 Rs. Invertebrate Neuroscience, 14(1), pp. $13-36$.

Forster, R., G. Bode, L. Ellegaard and J.W.Van der Laan (2010). The RETHINK Project on Minipigs in the Toxicity Testing of New Medicines and Chemicals: Conclusions and Recommendations. Journal of Pharmacological and Toxicological Methods, 62(3), pp. 236-242. 
Goldberg, A.M. (2010). The Principles of Humane Experimental Technique: Is It Relevant Today? Alternatives to Animal Experimentation, 27, pp. 25-27.

Gray, A.C., S.S. Sidhu, P.C. Chandrasekera, C.F.M. Hendriksen, C.A.K. Borrebaeck (2016). Animal-Friendly Affinity Reagents: Replacing the Needless in the Haystack. Trends in Biotechnology, 34 (12), pp. 960-969. [online] Available at: https://www. cell.com/trends/biotechnology/fulltext/So167-7799(16)30063-4 [Accessed 16 August 2018].

Groff, K., J. Brown, A.J. Clippinger (2015). Modern affinity reagents: Recombinant antibodies and aptamers. Biotechnology Advances, 33(8), pp. 1787-1798.

Gunatilake, M. (2016). Zebrafish, Danio Rerio as a Replacement Alternative. In: Asian Congress 2016 on Alternatives and Animal Use in the Life Sciences. Saga: Japanese Society for Alternatives to Animal Experiments. [online] Available at: http://www .asas.or.jp/jsaae/eng/events/pdf/asian2016/AS1-3.pdf [Accessed 16 August 2018].

Gunatilake, M., F. Busquet, M.A. Akbarsha (2014). Workshop Report: Alternatives Initiative in Sri Lanka: Pre- and Post-conference Workshops at the Inaugural Scientific Conference of the Sri Lanka Association for Laboratory Animal Science. Alternatives to Animal Experimentation, 31(2), pp. 224-226. [online] Available at: http://www.altex.ch/resources/altex_2014_2_224_226_Gunatilake1.pdf [Accessed 16 August 2018].

Helmholtz Centre for Environmental Research (2016). Fish and Amphibian Embryos as Alternative Models in Toxicology and Teratology, An International Symposium \& Workshop. France: Helmholtz Centre for Environmental Research (UFZ). [online] Available at: http://www.ufz.de/fish-frog-embryo/index.php?en=30159 [Accessed 12 January 2017].

Home Office (2014). Working to Reduce the Use of Animals in Scientific Research. UK Home Office Delivery Plan, February 2014. [online] Available at: https://assets. publishing.service.gov.uk/government/uploads/system/uploads/attachment_data/ file/277942/bis-14-589-working-to-reduce-the-use-of_animals-in-research.pdf [Accessed 12 January 2017].

Home Office (2015). Annual Statistics of Scientific Procedures on Living Animals Great Britain 2014. [online] Available at: https://assets.publishing.service.gov.uk/ government/uploads/system/uploads/attachment_data/file/469508/spanimals14 .pdf [Accessed 12 January 2017].

Humane Society International (2013). Press Release: Be Cruelty-free Campaign to End Cosmetics Animal Testing in China Launches with Pop Singer Wang Feifei, NGOs, and Industry. [online] Available at: http://www.hsi.org/news/press_releases/2013/o6/ bcf_china_launch_062813.html [Accessed 26 September 2016].

Institute for In Vitro Sciences (2014). European Association Supports Production of Training Videos for Non-Animal Tests. [online] Available at: http://www.prnewswire 
.com/news-releases/european-association-supports-production-of-training-videos -for-non-animal-tests-282413451.html [Accessed 19 September 2016].

Institute for Laboratory Animal Research (ILAR) (2011). Guide for the Care and Use of Laboratory Animals. 8th ed. Institute for Laboratory Animal Research. [online] Available at: https://grants.nih.gov/grants/olaw/Guide-for-the-Care-and-Use-of -Laboratory-Animals.pdf [Accessed 12 January 2017].

International Serum Industry Association (2017). How Is Bovine Serum Produced and Tested?. [online] Available at: http://www.serumindustry.org/faq.htm [Accessed 12 January 2017].

Jochems, C.E., van der J.B. Valk, F.R. Stafleu and V. Baumans (2002). The Use of Fetal Bovine Serum: Ethical or Scientific Problem?. Alternatives to Laboratory Animals, 30(2), pp. 219-228.

Kaiser, J. (2015). PETA Study Finds 'Dramatic' Rise in Use of Lab Animals in United States. Science, 25.2.15. [online] Available at: http://www.sciencemag.org/ news $/ 2015 / 02 /$ peta-study-finds-dramatic-rise-use-lab-animals-united-states [Accessed 12 January 2017].

Leschen, A.S. and S.J. Correia (2010). Mortality in Female Horseshoe Crabs (Limulus polyphemus) from Biomedical Bleeding and Handling: Implications for Fisheries Management. Marine and Freshwater Behaviour and Physiology, 43(2), pp. 135-147.

Lidbury, B.A. and A.M. Richardson (2012). A Pattern Recognition Bioinformatics Alternative System to Rodent Models in Fundamental Research, World Congress in Animal Alternatives in the Life Sciences. Alternatives to Animal Experimentation Proceedings, 1, Proceedings of WC8, pp. 515-520. [online] Available at: http://www .altex.ch/resources/515520_Lidbury21.pdf [Accessed 16 August 2018].

Lush Prize (2014). Lush Prize Conference 2014. [online] Available at: http://lushprize .org/2014-prize/lush-prize-conference-2014/ [Accessed 11 January 2017].

Lush Prize (2016). Story of the Lush Prize [video]. [online] Available at: https://vimeo .com/album/4224606/video/18934029o [Accessed 20 January 2017].

Lush Prize (2017a). About the Lush Prize. [online] Available at: http://lushprize.org/ awards / [Accessed 11 January 2017].

Lush Prize (2017b). Eligibility. [online] Available at: http://lushprize.org/awards/ eligibility/ [Accessed 11 January 2017].

Marks, J. (2012). Accept No Substitutes: The Ethics of Alternatives. In: S. Gilbert, G.E. Kaebnick and T.H. Murray, eds., Animal Research Ethics: Evolving Views and Practices. Hastings Center Report Special Report 42, no. 6. Hoboken: Wiley-Blackwell. [online] Available at: http://www.thehastingscenter.org/uploadedFiles/Publications/ Special_Reports/AnimalResearchEthics.pdf [Accessed 11 August 2018].

M'Barek, S., C. Pellevoisin, C. Chesné, F. Busquet and O. Souilem (2015). Workshop Report: First Training on Alternatives to Animal Experimentation in Tunisia. 
Alternatives to Animal Experimentation, 32(4), pp. 388-39o. [online] Available at: http://www.altex.ch/resources/WE_388_390.pdf [Accessed 16 August 18].

New England Anti-Vivisection Society (NEAVS) (2017). Laws and Regulations: Animal Welfare Act. [online] Available at: http://www.neavs.org/research/laws [Accessed 12 January 2017].

Nicholls, C. (2012). Zebrafish, the ${ }_{3} R$ R, and Animal Welfare Theory. A Historical Perspective. British Association of Zebrafish Husbandry.

Oredsson, S. (2013). Neurotoxicity, Genotoxicity and Metabolism of Salinomycin Analogs with Cancer Stem Cell Inhibiting Properties. Grants in 2013, Swedish Fund for Research Without Animal Experiments. [online] Available at: http://forskautandju rforsok.se/swedish-fund-for-research-without-animal-experiments/ grants/2013-2/ [Accessed 12 January 2017].

Organisation for Economic Co-operation and Development (OECD) (2017). Bovine Corneal Opacity and Permeability Test Method for Identifying i) Chemicals Inducing Serious Eye Damage; and ii) Chemicals Not Requiring Classification for Eye Irritation or Serious Eye Damage. Test no. 437. [online] Available at: http://www.oecd-ilibrary.org/ environment/test-no-437-bovine-corneal-opacity-and-permeability-test-method -for-identifying-i-chemicals-inducing-serious-eye-damage-and-ii-chemicals-not -requiring-classification-for-eye-irritation-or-serious-eye-damage_9789264203846 -en [Accessed 4 January 2017].

Organisation for Economic Co-operation and Development (OECD) (1992). OECD Guidelines for the Testing of Chemicals: Fish, Acute Toxicity Test. Section 2. Test No. 203 [online] Available at: http://www.oecd-ilibrary.org/environment/test-no -203-fish-acute-toxicity-test_9789264069961-en [Accessed 7 January 2017].

Ormandy, E.H., C.A. Schuppli and D.M. Weary (2012). Factors Affecting People's Acceptance of the Use of Zebrafish and Mice in Research. Alternatives to Laboratory Animals, 40(6), pp. 321-333.

Oxford English Dictionary (2016). Oxford University Press [online] Available at: http:// www.oed.com/view/Entry/273779?rskey=8flZF8\&result=1 [Accessed 7 January 2017].

Park, C.Y., S.H. Jung, J.P. Bak, S.S. Lee and D.K. Rhee (2005). Comparison of the Rabbit Pyrogen Test and Limulus Amoebocyte Lysate (LAL) Assay for Endotoxin in Hepatitis B Vaccines and the Effect of Aluminum Hydroxide. Biologicals, 33(3), pp. 145-151.

PETA International Science Consortium (2015a). Webinar 6 Video: Zebrafish Embryo Acute Tox [video]. [online] Available at: https://www.youtube.com/ watch?v=2zHNxiVnggo [Accessed 4 January 2017].

PETA International Science Consortium (2015b). Webinar Video 3 Eye Damage Irritation [video]. [online] Available at: https://www.youtube.com/watch?v=jSgozxPy wYo\&feature=youtu.be [Accessed 4 January 2017]. 
PETA International Science Consortium (n.d.). Alternatives Approved by Regulators. [online] Available at: https://www.piscltd.org.uk/alternatives/ [Accessed 4 January 2017].

Planchart, A., C.J. Mattingly, D. Allen, P. Ceger, W. Casey, D. Hinton, J. Kanungo, S.W. Kullman, T. Tal, M. Bondesson and S.M. Burgess (2016). Advancing Toxicology Research Using In Vivo High Throughput Toxicology with Small Fish Models. Alternatives to Animal Experimentation, 33(4), pp. 435-452. [online] Available at: https:// www.altex.org/index.php/altex/article/view/142/122 [Accessed 16 August 2018].

Reed, B. and M. Jennings (2011). Guidance on the housing and care of Zebrafish Danio rerio. Horsham: Royal Society for the Prevention of Cruelty to Animals. pp. 1-62.

Royal Society for the Prevention of Cruelty to Animals (RSPCA) (1980). Report of the Panel of Enquiry into Shooting and Angling (1976-1979), RSPCA Medway Report. Horsham: RSPCA.

Russell, W.M.S. and R.L. Burch (1959/1992). The Principles of Humane Experimental Technique. special ed. [online] Available at: http://altweb.jhsph.edu/pubs/books/ humane_exp/het-toc [Accessed 4 January 2017].

Seralab (2017). Foetal Bovine Serum. [online] Available at: http://www.seralab.co.uk/ cell-culture/foetal-bovine-serum [Accessed 11 January 2017].

Tannenbaum, J. and B.T. Bennett (2015). Russell and Burch's ${ }_{3}$ Rs Then and Now: The Need for Clarity in Definition and Purpose. Journal of the American Association for Laboratory Animal Science, 54(2), pp. 120-132. [online] Available at: https://www .ncbi.nlm.nih.gov/pmc/articles/PMC4382615/ [Accessed 16 August 2018].

Tanner, R. and H. McShane (2016). Replacing, Reducing, and Refining the Use of Animals in Tuberculosis Vaccine Research. Alternatives to Animal Experimentation, 34(1), pp. 1-10.

Taylor, K., N. Gordon, G. Langley and W. Higgins (2008). Estimates for Worldwide Laboratory Animal Use in 2005. Alternatives to Laboratory Animals, 36(3), pp. 327-342.

Thermo Fisher Scientific (2017). Serum Products Are Commonly Used in Cell Culture Research. [online] Available at: http://www.thermofisher.com/uk/en/home/life -science/cell-culture/mammalian-cell-culture/fbs/other-sera.html [Accessed 12 January 2017].

United States Department of Agriculture (USDA) National Agricultural Library (2017). Questions and Answers About the Animal Welfare Act and Its Regulations for Biomedical Research Institutions. [online] Available at: https://www.nal.usda.gov/awic/ questions-and-answers-about-animal-welfare-act-and-its-regulations-biomedical -research [Accessed 12 January 2017].

Van Vliet, E. (2011). Current Standing and Future Prospects for the Technologies Proposed to Transform Toxicity Testing in the 21st Century. Alternatives to Animal Experimentation, 28(1), pp. 17-44. [online] Available at: http://www.altex.ch/ 
all-issues/issue/1-11/current-standing-and-future-prospects-for-the-technologies -proposed-to-transform-toxicity-testing-in-the-21st-century [Accessed 16 August 2018].

World Health Organization (2016). Methods of analysis. 3. Biological methods. 3.5 Test for pyrogens. The International Pharmacopoeia. 6th ed. World Health Organization. [online] Available at: http://apps.who.int/phint/en/p/docf/ [Accessed 12 January 2017]. 